\title{
Facilitating Online Continuing Professional Development Opportunities in Technology- Enhanced Learning: the TELTA approach
}

\author{
http://dx.doi.org/10.3991/ijac.v8i4.5308 \\ P. Rooney \\ Dublin Institute of Technology, Ireland
}

\begin{abstract}
Information and communication technologies are fundamentally changing the way we live our lives. However, despite these huge societal changes, it is widely recognised that the potential of ICTs for enhancing teaching and learning has not yet been capitalised on in higher education, with traditional pedagogical methods still predominating. However it is crucial that educators are receptive to the potential of ICTs and that they have a sound understanding of this potential and how to capitalise on it. TELTA (TechnologyEnhanced Learning, Teaching and Assessment) is a fully online eight-week course offered by the Dublin Institute of Technology which aims to address these issues by giving participants the opportunity to immerse themselves in existing and emerging learning technologies. This paper provides a case study of the TELTA approach, exploring key areas including target audience, module goals, underpinning pedagogical framework, assessment methodologies, technologies utilised and future plans for further developing the initiative.
\end{abstract}

Index Terms-technology-enhanced learning, professional development, online

\section{INTRODUCTION}

Information and communication technologies are fundamentally changing the way we live our lives. However, despite these huge societal changes, it is widely recognised that the potential of ICTs for enhancing teaching and learning has not yet been capitalised on in higher education, with traditional pedagogical methods still predominating. However, given the fact that current students consider e-learning to be integral to their learning processes (HEFCE 2007), it is crucial that educators are receptive to the potential of ICTs and that they have a sound understanding of this potential and how to capitalise on it.

TELTA (Technology-Enhanced Learning, Teaching and Assessment) is a fully online eight-week course offered by the Dublin Institute of Technology which aims to address these issues by giving participants the opportunity to immerse themselves in existing and emerging learning technologies. Recognising the importance of sustaining online students' motivation, and the key role that empowerment plays in this regard, the course takes a unique pedagogical approach whereby participants set their own personal learning objectives, thereby enabling them to engage with weekly themes from their own professional perspectives. Continuing this empowering approach, the course is underpinned by a problem-based learning pedagogy whereby participants engage in collaborative group activities which require them to explore and adopt ICTs for their specific pedagogical purposes. Recognising the increasingly connected society that we now live in, building a community is crucial to our approach and activities encourage TELTA participants to extend their personal learning networks beyond the TELTA classroom. By taking this immersive and connectivist approach, TELTA aims to motivate and empower participants to take advantage of the potential of ICTs for them and for their students. By setting their own personal learning objectives for the course, we aim to optimise course relevance for participants, thereby ensuring maximum impact on future teaching and learning practices.

\section{THE TELTA APPROACH}

\section{A. Target Audience}

TELTA is aimed at all participants from both public and private sectors: previous teaching experience is not required. The course is formally assessed at Level 9 on Ireland's National Framework for Qualifications (http://www.qqi.ie/Pages/National-Framework-of-Qualific ations-\%28NFQ\%29.aspx) and on successful completion, participants gain 5 ECT credits (in line with the established European Credit Transfer System.) These credits can be used towards other postgraduate programmes offered by the Dublin Institute of Technology (specifically the MA in Higher Education) or they can contribute towards continuing professional development (CPD) portfolios. Participants should hold at least an Honours Level 8 primary degree (or equivalent international qualification). Applications from candidates without a suitable primary degree but with relevant and appropriate practical experience are also encouraged: such applications are assessed in line with established RPL (Recognition of Prior Learning) procedures within the institution.

\section{B. Module Goals}

Since 2003, the Learning, Teaching and Technology Centre at the Dublin Institute of Technology has run the award-winning Dublin e-Learning Summer School (http://dublinelss2015.wordpress.com), which has been accredited as part of a 5 ECTs credit module since 2012. Demand for places on this course is consistently high and places are highly sought after indicating the significant demand for accredited professional development in the area of e-learning. The annual waiting list for places and recurring queries regarding other $\mathrm{CPD}$ opportunities in this area indicated that additional options were required in order to satisfy demand. 
TELTA aims to satisfy this demand. Specific goals of the course are:

(1) Satisfy the demand for flexible, accredited professional development in the field of e-learning, by providing an online course which runs at least twice a year. TELTA aims to offer greater flexibility for participants while also expanding opportunities for accredited professional development.

(2) Give participants the opportunity to gain an insight into what it is like to be an online student. Donnelly and O'Rourke (2007) argue that in order to gain the necessary experience and confidence to move their own teaching practice to an online environment, lecturers would benefit from gaining first-hand experience as an online student. As a fully online course facilitated by elearning experts, TELTA provides this opportunity through its range of webinars, resources, online tutorials and facilitated online synchronous group work.

(3) Provide participants with the time and space in which to immerse themselves in, and reflect on, existing and emerging learning technologies. Given the increasingly pervasive nature of information and communication technologies (ICTs), it is crucial that educators are receptive to their potential and that they have a sound understanding of this potential and how to capitalise on it during the teaching and learning process. The TELTA curriculum is designed to expose participants to, and give them experience in using, a wide range of technologies and activities are designed with this in mind. Additionally participants are encouraged to reflect on their TELTA experiences and wider e-learning practices: for this purpose they are required to maintain a reflective blog for the duration of the course which forms part of the summative assessment. To successfully achieve the 5 ECTs accreditation of TELTA, participants commit in the region of 100 hours to the course (over eight weeks), between weekly webinars, online work and personal study time.

(4) Give participants the opportunity to discuss meaningfully with like-minded peers how technologies can be utilised with their students to enhance and enrich their learning, teaching and assessment experiences at higher education level. Recognising the increasingly connected society we now live in, building a community is crucial to our approach. Thus activities are not only highly collaborative, they also encourage participants to extend their personal learning networks beyond the TELTA classroom, using a range of social media in this regard. Examples of such tools include Twitter (http://www.twitter.com/) - which is used is used as a "backchannel" to the course using the hashtag \#dittelta and Diigo (http://www.diigo.com) - a social bookmarking tool which participants are encouraged to use for the sharing and annotation of resources. By taking this connectivist approach, we aim to highlight the importance of social networks in navigating and constructing knowledge in today's "connected" society (Siemens 2005, Ifhentaler et al. 2014).

(5) Sustain student engagement with the course and maximise relevance by adopting a personal learning objective (PLO) approach. The course takes a unique pedagogical approach whereby participants are required to set their own personal learning objectives at the outset, thereby enabling them to engage with weekly themes from their own professional perspectives. Continuing this im- mersive and empowering approach, the course is underpinned by a problem-based learning pedagogy whereby participants are required to engage in collaborative group activities which require them to explore and adopt ICTs for their specific pedagogical purposes. By enabling participants to set their own personal learning objectives for the course, we aim to optimise course relevance for individual participants, thereby ensuring maximum impact on participants' future teaching and learning practices.

\section{PEDAGOGICAL FRAMEWORK:}

The course design of TELTA is underpinned by a range of constructivist learning theories notably experiential learning, problem-based learning and connectivist learning. The course team (Dr. Pauline Rooney, Dr. Frances Boylan and Dr. Kevin O'Rourke) made the decision to underpin the course with a predominately experiential learning model, whereby "knowledge is created through the transformation of experience." (Kolb 1984, p.41). Thus we adopt a variety of teaching methods, including collaborative group work, independent learning activities (which involve a significant level of experimentation with emerging technologies), student-led discussions, reflective writing and self and peer evaluation. We consider that these activities enable participants to gain first-hand experience of using different technologies and media for a range of pedagogical purposes, while also allowing them the space to reflecting on these experiences and how they might inform their future teaching and learning practices.

Within this experiential learning model, the course is also underpinned by a problem-based learning pedagogy whereby participants engage in individual and collaborative group activities which require them to explore and adopt technologies for specific pedagogical purposes. In integrating both problem-based and experiential models of learning, we also adopt a flipped classroom approach (Educause 2012) whereby students are expected to engage with a range of relevant resources and complete individual and collaborative problem-based activities in advance of the weekly webinar. These webinars are then focused on exploring, reflecting, discussing and sharing experiences of resources and activities undertaken during the previous week.

Throughout the course, tutors are actively involved in contributing to, and moderating, online discussions, and in providing support, advice and guidance to participants. We encourage all participants to post issues or questions (both technical and non-technical) to the discussion boards where they can be guaranteed a prompt response: tutors can also be contacted directly via email and we run weekly lunchtime "office hours" via Blackboard Collaborate where participants can also get the opportunity to speak with tutors and/or their peers.

\section{A. Themes:}

A wide range of themes are covered in TELTA and participants are encouraged to explore these, keeping in mind their personal learning objectives for the course. Themes covered include:

- Exploring the current e-learning landscape

- Content and resources: sourcing free e-learning resources, developing e-learning content, integrating technologies into the curriculum 
- Communication: online student-faculty communication, netiquette, developing your personal learning network

- Teaching online, student activity and collaboration: roles and skills of the online tutor, designing collaborative activities, motivating and engaging students

- Mobile learning

- eAssessment

- Digital futures: e-learning trends, emerging technologies, national and international digital age ndas

\section{B. Assessment:}

In order to achieve the 5 ECTs accreditation of the course, participants are required to:

- engage in a series of short continuous assessments completed over the course of the module. Some of these assessments are collaborative in nature whilst others can be completed on an individual basis. Participants must complete all, and pass a minimum of four, of these seven continuous assessments.

- develop and maintain a reflective journal throughout the duration of the module. This work is assessed with reference to a reflective writing rubric which can be viewed at https://dittelta.files.wordpres s.com $/ 2014 / 01 /$ cpd-telta-reflective-writingrubric1.pdf.

Both parts of the assessment (i.e. the continuous assessments and the reflective journal) must be passed in order to achieve accreditation.

\section{Technologies:}

From a technical perspective, key technologies and media that are used to run the course include:

- Blackboard (http://webcourses.dit.ie): this is DIT's institutional virtual learning environment (branded "webcourses" within the institute) and it is used as the underpinning platform of the course.

- Blackboard Collaborate (http://www.blackboard.co $\mathrm{m} /$ platforms/collaborate/overview.aspx) is used to facilitate all webinars (again due to DIT's existing license for the product).

- Twitter (http://www.twitter.com) is used as an additional "backchannel" to the course, enabling participants to connect outside of Blackboard while also giving them the opportunity to extend their personal learning networks beyond the TELTA cohort. Participants are asked to use the hashtag \#DITTELTA to identify course-related tweets and a Twitter list (which participants are encouraged to subscribe to) is also used to curate participant tweets thus allowing participants to follow each other's tweets more easily.

A range of other tools and apps are also used throughout the course (see https://dittelta.wordpress.com/tools/ for examples of some of the tools used by previous students) and we actively encourage participants to experiment with, and explore new and emerging technologies, and share their experiences with the group.

\section{Feedback to date:}

TELTA was first launched in March 2014 and, to date, has been run with three cohorts of students (totalling thirty
53 participants): the majority of these participants have come from the higher education sector, most working in academic/lecturing roles. The majority have come from Irish institutions/companies with three participants coming from Singapore.

Feedback to date has been generally very positive, as indicated by a selection of quotes below (which came from anonymous student evaluations of the course).

"Re. student engagement, there was plenty of opportunity and encouragement to interact during the weekly webinar. The live online webinar was in face a more inclusive, interactive and stimulating environment than most class-based lectures I have attended"

"There was of fun and enjoyment to this module. It was professionally run. The tutors were fantastic with the course well run and designed. I have learned so much from this module in not only learning from the literature but to how an online class is delivered and what it feels to be that online student! So much to take away from this module going forward into the future! Thank you!!!"

"I really loved the weekly webinar. The sessions were lively, entertaining and hugely informative. A good sense of class community was built up quite easily - facilitated both by discussions during the weekly webinar and also through the collaborative activities students were required to organise independently. It gave a huge insight to students' experiences in a fully online environment and I would definitely recommend any academic thinking of moving some of their teaching online to take this module. I also feel that the structured exercises during the module have taught me some valuable practical skills - the fact that we were essentially forced to use new tools to complete particular exercises meant that not only did we learn some of the theory underpinning elements of e-learning but we also gained experience of the tools themselves and the realisation that many useful and free online tools are simple enough to learn independently in an hour or two."

A sample of further student reflections on the course can be viewed at: https://www.youtube.com/watch? $\underline{\nu}=$ Vdtd0RS2L5I\&feature =youtu.be.)

\section{E. Future plans}

Baume (2003, p.77) states that monitoring involves first asking "How is it going?" and secondly asking "How should we change what we are doing?" Similarly evaluation involves asking similar questions at mid or end points of an educational activity. In undertaking such monitoring and evaluation, the overall goal is to make a judgment about a programme or activity, with a view to informing future decisions in order to improve the effectiveness of the activity (Patton, 1987). Based on the monitoring and evaluation activities undertaken during TELTA to date, a number of plans have been made to further develop the course, some of which have already been undertaken.

Based on student feedback, the course assessment has been re-designed to include a more significant component of continuous assessment. The new assessment procedures can be viewed at https://dittelta.wordpress.com/ assessment/. Assessment rubrics for each assessment have also been designed in order to give students a clear indication of the criteria against which their submissions would be marked. 


\section{FACILITATING ONLine CONTINUING PROFESSIONAL DEVELOPMENT OPPORTUNiTIES IN TECHNOLOGY-ENHANCED...}

Discussions are also currently underway regarding the possibility of delivering some aspects of the course as independent "bitesize" open continuing professional development offerings. Underpinning this strategy is the intention of maximising the flexibility of TELTA and catering for those who are keen to upskill but who are unable to commit to a 100 hour work load at the present time. Such continuing professional development offerings would be accredited via Open Badges.

\section{ACKNOWLEDGMENT}

Sincere thanks go to Dr. Frances Boylan and Dr. Kevin O'Rourke, whose expertise, professionalism and creativity have helped to make TELTA such a success.

\section{REFERENCES}

[1] D. Baume, Monitoring and Evaluating Staff and Educational Development. In: Kahn, P. and Baume, D. (Eds.) A Guide to Staff and Educational Development. London and New York: Routledge, 2003.

[2] R. Donnelly \& K.C. O’Rourke, "What now? Evaluating eLearning CPD Practice in Irish Third-Level Education." Journal of Further \& Higher Education, vol.3, iss. 1, pp. 31-40, 2007. http://dx.doi.org/10.1080/03098770601167864

[3] Educause, 7 Things You Should Know About Flipped Classrooms. Available from: https://net.educause.edu/ir/library/pdf/ELI70 81.pdf, 2012.

[4] HEFCE (Higher Education Funding Council for England) In Their Own Words: Exploring the Learner's Perspective on E-Learning. JISC, 2007.

[5] D. Ifenthaler, A.B. Adcock, B.E. Erlandson, M. Gosper, S. Greiff, P. Pirnay-Drummer, "Challenges for education in a connected world: Digital learning, data rich environments, and computerbased assessment-Introduction to inaugural special issue of Technology, Knowledge and Learning." Technology, Knowledge

$$
\text { and Learning. vol.19, pp. 121-126, } 2014 .
$$
http://dx.doi.org/10.1007/s10758-014-9228-2

[6] D.A. Kolb, Experiential Learning: Experience as the Source of Learning and Development. New Jersey: Prentice-Hall, 1984.

[7] G. Siemens, "Connectivism: a theory of learning for the digital age". International Journal of Instructional Technology and Distance Learning, vol. 2, iss. 1. Available from: http://www.itdl.org/journal/jan 05/article01.htm, 2005

\section{AUTHOR}

Dr. Pauline Rooney works in elearning development with the Dublin Institute of Technology, Ireland, where she supports lecturers as they engage with technology enhanced learning. She coordinates, and lectures on, accredited postgraduate courses offered by DIT, and she supervises postgraduate research students, specialising in education/elearning. Pauline also works as an Expert Evaluator of European Commission-funded projects and has worked with the European Commission's Horizon 2020 Research and Innovation programme in this role. She is a Fellow of SEDA (the UK Staff Educational Development Association) and she is a member of the academic review panel for a number of academic journals and conferences including Innovations in Education and Teaching International, the International Journal of Social Research Methodology, Simulation \& Gaming and the International Journal of Game-Based Learning. (email: pauline.rooney@dit.ie).

This paper describes one of the 2015 IELA Award winning projects (http://www.ielassoc.org/awards program/past_winners.html). Submitted, 25 October 2015. Published as resubmitted by the author 30 November 2015 . 